\title{
CORRECTION
}

\section{Correction: A phase 2 randomised study of veliparib plus FOLFIRI \pm bevacizumab versus placebo plus FOLFIRI \pm bevacizumab in metastatic colorectal cancer}

Vera Gorbunova ${ }^{1}$, J. Thaddeus Beck ${ }^{2}$, Ralf-Dieter Hofheinz ${ }^{3}$, Pilar Garcia-Alfonso ${ }^{4}$, Marina Nechaeva ${ }^{5}$, Antonio Cubillo Gracian ${ }^{6}$, Laszlo Mangel ${ }^{7}$, Elena Elez Fernandez ${ }^{8}$, Dustin A. Deming ${ }^{9}$, Ramesh K. Ramanathan ${ }^{10}$, Alison H. Torres ${ }^{11}$, Danielle Sullivan ${ }^{11}$, Yan Luo ${ }^{11}$ and Jordan D. Berlin ${ }^{12}$

British Journal of Cancer (2019) 121:429-430; https://doi.org/10.1038/s41416-019-0528-0

Correction to: British Journal of Cancer (2019) 120, 183-189; https://doi.org/10.1038/s41416-018-0343-z; published online 11 December 2018

The original version of this article contained an error in Fig. 1 a. The number of patients at risk listed in the Veliparib arm of Fig. 1a should have read " 65 " instead of " 35 ". The correct figure is below.

\begin{abstract}
(c) (i) Open Access This article is licensed under a Creative Commons By Attribution 4.0 International License, which permits use, sharing, adaptation, distribution and reproduction in any medium or format, as long as you give appropriate credit to the original author(s) and the source, provide a link to the Creative Commons license, and indicate if changes were made. The images or other third party material in this article are included in the article's Creative Commons license, unless indicated otherwise in a credit line to the material. If material is not included in the article's Creative Commons license and your intended use is not permitted by statutory regulation or exceeds the permitted use, you will need to obtain permission directly from the copyright holder. To view a copy of this license, visit http://creativecommons. org/licenses/by/4.0/.
\end{abstract}

(c) The Author(s) 2019

\footnotetext{
${ }^{1}$ N.N. Blokhin Russian Cancer Research Center, Moscow, Russia; ${ }^{2}$ Highlands Oncology, Rogers/Fayetteville, AR, USA; ${ }^{3}$ Interdisciplinary Tumor Center, University Hospital Mannheim, University of Heidelberg, Heidelberg, Germany; ${ }^{4}$ Hospital General Universitario Gregorio Marañón, Madrid, Spain; ${ }^{5}$ Arkhangelsk Clinical Oncology Center, Arkhangelsk, Russia; ${ }^{6}$ Centro Integral Oncológico Clara Campal Hospital Universitario Madrid Sanchinarro, Madrid, Spain, and Departamento de Ciencias Médicas Clínicas, Universidad CEU San Pablo, Madrid, Spain; ${ }^{7}$ Pecsi Tudomanyegyetem Klinikai Kozpont, Onkoterapias Intezet, Pécs, Hungary; ${ }^{8}$ Vall d'Hebron University Hospital, Barcelona, Spain; ${ }^{9}$ University of Wisconsin, Madison, WI, USA; ${ }^{10}$ Mayo Clinic, Scottsdale, AZ, USA; ${ }^{11}$ AbbVie Inc., North Chicago, IL, USA and ${ }^{12}$ Vanderbilt-Ingram Cancer Center, Nashville, TN, USA Correspondence: Jordan D. Berlin (jordan.berlin@vumc.org)
}

Published online: 26 July 2019 
a

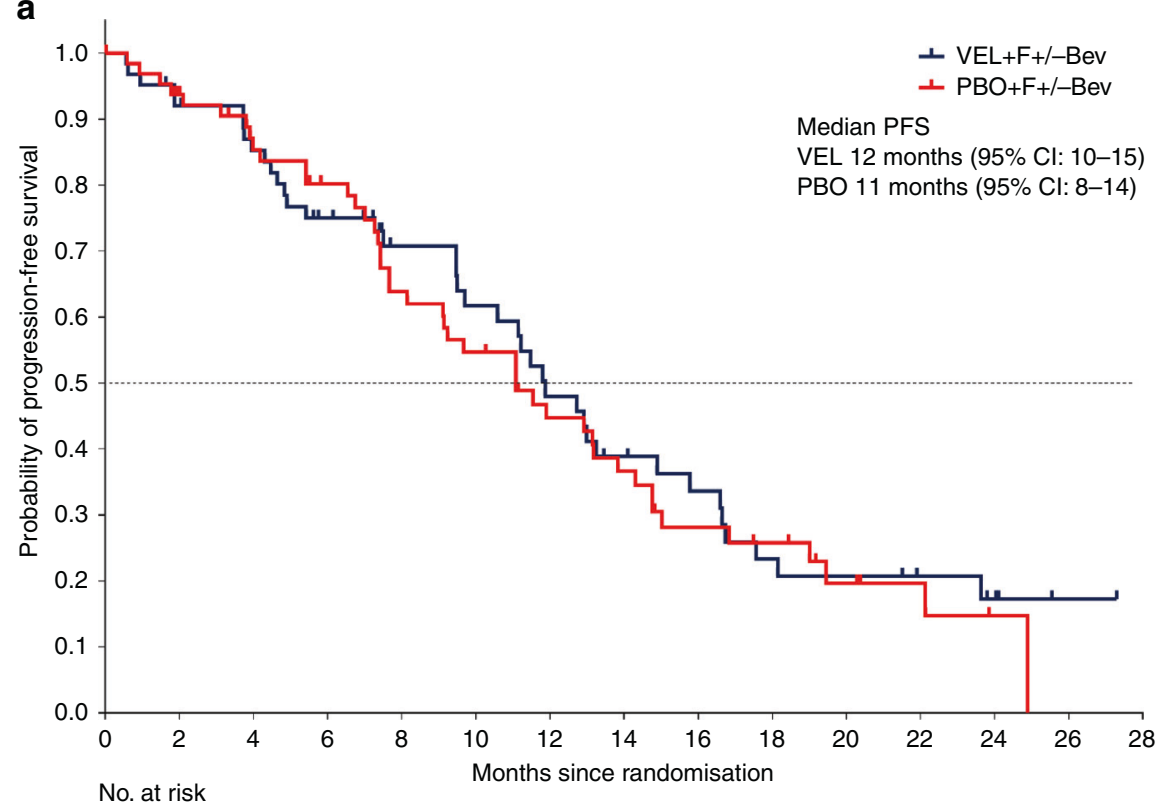

$\begin{array}{llllllllllllllll}\text { VEL } & 65 & 57 & 51 & 42 & 31 & 27 & 22 & 16 & 14 & 9 & 8 & 7 & 5 & 1 & 0\end{array}$ $\begin{array}{lllllllllllllll}\text { PBO } & 65 & 58 & 51 & 44 & 35 & 29 & 23 & 19 & 12 & 10 & 6 & 4 & 2 & 0\end{array}$

b

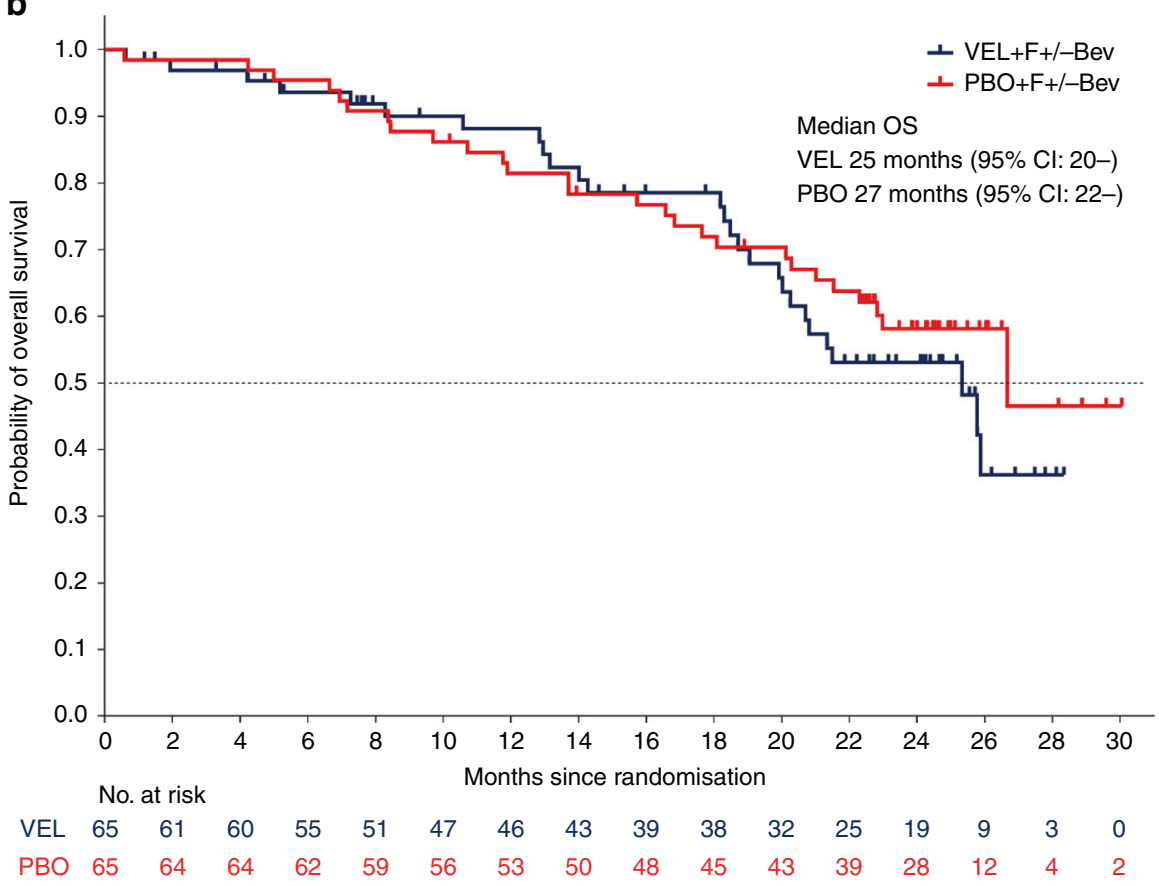

Fig. 1 a Progression-free survival at final analysis and $\mathbf{b}$ overall survival at final analysis. $\mathrm{Cl}$ confidence interval, PBO placebo $+\mathrm{FOLFIRI} \pm$ bevacizumab, VEL veliparib + FOLFIRI \pm bevacizumab 